\title{
The Level Of Positive Thinking And Its Relationship To The Level Of Behavioral Disorders Among Students Of Princess Alia University College
}

\author{
DR. Nieveen Mohammad Abuzai \\ Balqa Applied University_Jordan. dr.nieveenabuzaid@icloud.com
}

\section{Introduction:}

Thanks to his divine honor from the rest of creation by the grace of thinking, man carries the most powerful weapons of life within his mental skills, as he possesses what charges his energies in the face of crises to produce the words with which his forearm strengthens, and with which he strengthens himself, and combats the successive pressures on his being, which threaten our human being and our steadfastness Emotional, and our mental capabilities.

Thinking is the only mechanism that provides a person with the opportunity to control his world, bypassing various turns without side effects, and without changing directions or succumbing to negative solutions, when the forces that paint the image of our strength coming from the inside through Positive thinking are weakened (Kattami et al., 2017).

Scott W. believes that Positive thinking is the drive to reach the best, as it is the secret behind the highest achievement and promotes the work environment with openness, honesty and confidence, and since the behaviors of the individual are a reflection of all his convictions and all that highlights his vision and thinking, so it determines our balance of the health

Behavioral disorders appears in the logical analysis to be the result of frustrating situations, and the non-positive thinking practiced by the individual, which leads him to a lower level of performance, and it involves under one of the different classifications of Behavioral disorders according to what he practices from the performance that reflects his intellectual lack of preparation, his tendency to aggression or
Isolation and indifference are the effects of abnormal thinking on an individual's behavior.

The study Problem:

Man moves through different stages of growth, qualitative shifts in his thinking and skills, as each stage carries its different characteristics and developmental requirements, and these qualitative shifts control the areas of growth that grow consistently in all its areas, and the most prominent thing that the individual needs through the stages of his life and since its beginnings is the support that goes beyond the concept of Filling material needs to enhance capabilities regardless of their level, according to the principles of the brain that emphasize the importance of positivity, enjoyment and happiness to support mental development and thus support the selfconstruction that controls the individual's behavior and emotions, reduces the incidence of disorders and builds psychological hardness.

The current research deals with Positive thinking among the students of Princess High University College, and their Behavioral disorders, and also reveals the correlation between Positive thinking and Behavioral disorders, which confirm previous studies about the possibility of prevention, and treatment of them by employing Positive thinking that pushes the student to academic progress, and strengthens the role of the academic institution in Develop their personalities and solve their problems.

The problem of this study is determined by the following main question:

What is the correlation of Positive thinking to Behavioral disorders among a sample of female students at Princess Aley University College? To 
answer this question, the following sub-questions can be formulated:

1. What is the level of Positive thinking among the students of Princess Higher University College?

2. What is the level of behavioral disorders among Princess Aley University College students?

3. Is there a statistically significant correlation between Positive thinking and Behavioral disorders among students of Princess High University College?

Study hypotheses:

- There is no statistically significant correlation at the level of significance $(\alpha=0.05)$ in the level of Positive thinking and Behavioral disorders among students of Princess Aley University College.

Aims of the study:

This study aims to investigate the correlation between Positive thinking and Behavioral disorders among a sample of Princess Aley University College students, and the positive thinking level of Princess Aley College students, and also the most prominent Behavioral disorders among the first-year college students.

The importance of study:

\section{The theoretical significance of the study}

It is considered the first studies to the researchers' knowledge in linking Positive thinking and Behavioral disorders, which supports their theoretical importance, content and results.

Provides a theoretical framework on the importance of Positive thinking and analyzes its skills and relevance to undergraduate students and teachers.

The study reveals the type and level of Behavioral disorders in a sample of university students.

\section{Applied importance:}

-Contributing to providing a theoretical course that can be used in solving behavioral crises and phenomena that hinder the academic and psychological progress of students and universities, which constitutes the greatest challenge to society.

-It may increase academic and social achievement because Positive thinking provides an open mind and build myself tolerant and proactive.

-Reducing behavioral problems that are unacceptably common in university corridors on campus.

\section{Procedural definitions:}

Positive thinking: a set of mental skills that increases the effectiveness and energy of the individual to the highest possible extent by investing positive emotions.

Procedurally, it is defined as the score a student gets on Positive thinking.

\section{Behavioral disorders:}

The research adopts Grobard's definition (1973) which defined it as a variety of markedly deviant and extreme behaviors, and repetitive, and contrary to the expectations of the observer, represented in impulsivity, aggression, depression, and withdrawal.

Procedurally, it is defined as the student's score on Behavioral disorders.

\section{Princess High University College:}

An official Jordanian college for women, which is one of the colleges affiliated with the AlBalqa Applied University, and is distinguished by applied education at the level of bachelor's and intermediate diploma, and the college also awards scientific degrees at the master's level. The high ownership of Al-Balqa Applied University was established in 1996 to include all governmental community colleges, and in 2000 the college was transformed into a university college.

\section{Female students of Princess Alia University College:}

All students enrolled in undergraduate and admissions programs at Al-Balqa Applied University / Princess Aley University College Branch for the 2019/2020 academic year.

\section{Limits and limitations of the study:}

The results of the study are limited in light of the following limitations: 
Human Limits: The study sample is one of the first year students of the Department of Psychology and Special Education, the Department of Educational Sciences, the Department of Administrative Sciences, and the Department of Basic Sciences.

Temporal limits: where the study was applied during the second semester of the 2019/2020 academic year.

Spatial boundaries: Princess Alia University College / Al-Balqa Applied University.

Limitations of the study: The results of this study are determined by the tools used and their psychometric characteristics represented by the tools that the researchers used in accordance with the research variables

\section{Theoretical framework:}

Positive words and calls for broad-minded thinking and positivity in behavior are the most popular content in popular books and publications. This is because it captures our thinking and stimulates the impulses that rise up with a word that speaks to the mind, as if it issued a judgment against him for immediate implementation, and the siren sounded, announcing the state of enjoyable and purposeful work.

The negative trend in thinking is what distinguishes all those diagnosed prisoners of psychological stress, chronic mental illness, the lack of alternatives, waiting for the worst event, the inauspicious tomorrow, the harshest night, and the deeper sadness, all of which break resilience and threaten psychological hardness and dispel ambition, and reduce achievement or even Desire for life.

Based on the studies now centered on Positive thinking, and its most effective role in preventing and countering the inequality in our psychological states, remedial programs have begun to rely on Positive thinking skills in their design, procedures and tools. These are the results of the positive psychology movement 1998 called by Martin Seljman, president of the American Psychiatrists Association. When he emphasized that psychology studies strengths, and invests them to support people, improve their lives, achieve happiness, help solve problems, support mental health and psychological harmony.

Seljman and Powellsky know it as investing the positive outputs of the mind in everything that is constructive and to get rid of negative processes and replace them with positive emotions (Seljman, 2003).

This is what the university student needs during the stage of qualifying study for the labor market and productivity, building healthy social relations, familiarity, achieving goals and independence, but defects in social upbringing, or various environmental, cultural, or economic factors, or failure to adapt to change in life stages, specifically The sensitive university stage, in which the student moves to broader options, a wide space for movement, change, and the spread in his world, and reveals any defect or weakness in himself, and his thinking style in the form of disordered, unacceptable, and maladaptive behavior.

Positive thinking refers to positive expectations, belief in ability, will, and the formation of positive mental systems that support the distinct and healthy psychological construction that directs behavior towards happiness and satisfaction, achieving goals despite faltering, and building a strong self that has psychological rigidity, which is immune to Being affected by the factors of both Which accustomed to the individual with psychological disorders that appear in the form of abnormal behaviors, unacceptable for the individual based on his gender, culture, age or social position.

The interest in the issue of Behavioral disorders is due to the developments surrounding the human being of environmental, social and other factors that are stressful (Abu Alia and Melhem (1998).

Apter (1982) argues that the term Behavioral disorders refer to different forms of non-adaptive behaviors that deviate from what is expected of them depending on their characteristics and location. 
The names of Behavioral disorders vary according to the theoretical literature, including:

Adjustment problems, social disability, emotional disability, delinquency, maladjustment, mental illness

And a lot of designations that indicate disagreement between researchers, due to the difference in the criterion, the reason for naming, the research topic, or interests.

As for the causes of abnormal and disturbed behavior, they are different, varied and frequent, and differ from the specific criteria for the individual according to his position or the different determinants of his life.

The criteria by which to identify Behavioral disorders are:

Repetitivebehavior:how long the behavior occurred,the severity of the behavior.

What distinguishes disordered behavior from non-disruptive behavior is a set of criteria, including:

- Social norm: that is, that is compatible with the customs, traditions and norms of society.

- Statistical criterion: that is deviates from the arithmetic mean of the behavior of the rest.

Self-standard: that is not satisfactory for the person himself.

The ideal criterion: a deviation from ideal mental health.

The natural standard: that is deviated from the original natural order.

Clinical Integrative Standard: that includes criteria for adaptation, complementarity, maturity, self-satisfaction, and community safety.

Whereas, behavioral disorders are functioning disorders, described as severe, attract attention, and do not conform to community norms (Rimawi, 2004).

There are many classifications of behavioral disorders, including the Educational Classification of Behavioral Disorders Kwi (1972) and he collected a wide range of information from educators, parents and records until he reached four basic classifications of behavioral disorders, namely:
1. Conduct disorders, personality disorders, immaturity, and social delinquency:

Among the procedures of this study, the responses of teachers, parents, and students were collected on an electronic questionnaire asking them to identify the most prominent Behavioral disorders among university students, and the recurrent disturbances were more than five times in a sample of (468) responses, which are:

-Thought disturbances (decision-making, problem-solving, and prioritization).

-Personal disturbances (isolation, excessive openness to communication, dullness, lack of adaptation, failure to manage social correlations, low motivation), Eatingdisorders, Sleep disorders.

-Low achievement and lack of motivation problems.

-Imitation and choosing inappropriate models of behavior and appearance.

-Lying, cheating, carelessness, shouting, mood swings.

Various studies also indicate the importance of improving the quality of thinking in order to modify individuals' behavior, and enable them to manage themselves and its various elements of life and manage success.

\section{Previous studies:}

No Arab or foreign study has been conducted that brings together the variables of the study - according to the limits of the researcher's knowledge - but many studies have dealt with Positive thinking and its role in mental health, including:

A study ofChenafeh et al (2017), aimed to identifying the role of a positive thinking program for psychological rehabilitation among a sample of university students in Iran. A tool for positive thinking and mental health was developed, and a training program consisted of (12) sessions for the purposes of the study, whose sample consisted of (103) university students, who were divided into the experimental and control groups and randomly. Both groups were exposed to the pretrial scale. After implementing the program, a telemetry was applied, and the results showed the effectiveness of the training program in reducing 
mental disorders and diseases, and that Positive thinking protects against the chain of mental illnesses.

The study ofShishin Wong ( 2012), which aimed to reveal the correlation between positive thinking, negative thinking and psychological compatibility among university students, and the sample consisted of (398) students from Singapore, and the researchers used the Positive thinking scale and the psychological compatibility scale, and the results of the study indicated that more females Males are prone to stress, and that negative thinking has a statistically significant positive correlation with depression, stress, anxiety, and inversely with life satisfaction.

The study of Grek, Obalia and Simmons (2000), that targeted the development of Positive thinking for students who face psychological pressure on a sample of (60) students. The students were divided into two experimental and control groups. Positive thinking scale was used, the psychological stress scale, and the threedimensional test, and concluded The results indicate an improvement in the experimental group score over the control group on Positive thinking test, stress scale and the three dimensions test.

Abdullah's study (2017) aimed to identify the level of Positive thinking and its correlation to life satisfaction and perfectionism among a sample of university students. The sample consisted of (100) male and female students from the Faculty of Education at Ain Shams University. The Ibrahim's scale (2010) was used, the perfectionism scale prepared by the researcher, and the life satisfaction scale. The study found an inverse correlation between Positive thinking and perfectionism and the like between life satisfaction and perfectionism, and a positive correlation between Positive thinking and life satisfaction.

The study of Mutrash and Dredd (2013) aimed at identifying the correlation between Positive thinking and academic self-motivation, and the direction towards the teaching profession among students of the College of Education at
Baghdad University and Al-Mustansiriya University. The sample was from (344) male and female students and the Abraham Scale (2010) for Positive Thinking and the Academic Motivation Scale (2010) were applied. The study revealed a positive correlation between motivation and Positive thinking and also an increase in the level of Positive thinking among males.

The study ofToth et al. (2018), which aimed to identify eating disorders and their prevalence among university students in three different universities in Ukraine, Poland and Hungary, and their correlation to the behavioral profile of (1965) students, (534) in Hungary, (708), In Poland and (723) in Ukraine) a university student where a questionnaire was used to collect information from students on age, gender, marital status, physical problems, physical fitness, height, width and weight, and the SKOFF scale was also used to scale eating disorders. The DASS scale was also used to detect stress, depression and anxiety, and the results revealed that the prevalence of eating disorders in Hungary (21\%), (19.7) in Poland and (36.9) in Ukraine. The results showed that girls are more likely than males to have eating disorders, and that unmarried women are more likely than married couples to have eating disorders, and that the prevalence of eating disorders among university students in general is (26.4\%).

The study of Al-Ziyabat et al. (2014) aimed at recognizing the mental health of undergraduate students, and providing evidence for administrators, educators, and health care providers. The research paper emphasized the prevalence of some mental disorders and that failure to address them will lead to negative consequences for the individual, his family, and society, and lead to low achievement. Failure to diagnose it leads to an exacerbation of the problem, and leads to self-assault, increased unemployment, family problems, and disintegration in the fabric of society, and thus researchers recommend university departments and educators to play a role in coordination to employ psychological services for students, for 
awareness and treatment, to provide Better life opportunities for students, their families, and their community.

The study of Xue (2007) aimed at identifying the anxiety of Chinese girls at the university level and its effect on mental health on a sample of (847) female students, and the results showed the presence of psychological disorders and frustration to a large degree among these students, which affects the level of mental health of the students and recommends The study is concerned with the status of psychological students.

Al-Ansari's study (1997) aimed at identifying psychological disorders among youth in the State of Kuwait. The sample consisted of (1129) high school students and (938) university students. The results showed that shame, shame, remorse, anger, sadness, fear, confusion, depression, and discontent are the most important problems of youth.

A number of previous studies reached the same result of the research and confirmed a positive correlation between Positive thinking, compatibility and mental health, and met with the message in the characteristics of the sample and all of them studied the university community. As for the study of Abdullah (2017), the study of Mutrash and Dred (2013) agreed with the current research by the type of sample, but it is It studied positive variables and revealed the results about the positive correlation between these variables and Positive thinking and its role in promoting them, in contrast to the type of the second variable in the current research that combines with Positive thinking a negative correlation, and the current research sample was of almost the same age group, ranging between teenagers and others.

Method and procedures:

This chapter provides a description of the study population, the method for selecting the sample, the study tools used, and methods for presenting and preparing them. This chapter also describes the procedures taken by the researcher in codifying and applying study tools, and the statistical methods he relied on in analyzing the study. The following is a description of the previous elements.

Study methodology:

The nature of the present study necessitated the use of the relational descriptive approach to achieve the objectives of the study; and validate her hypotheses. It is one of the types of descriptive approaches, which is used in measuring the correlation between two variables, determining the nature and direction of the correlation, and then predicting a certain level of significance in digital form.

\section{Study population:}

The study community represents all students of Princess High University College admitted in the first semester of the academic year 2019/2020, and their number is (647) students, as the firstyear students in each major are as follows: Library Administration (26), psychological counseling (83), economics My home (60), special education (101), English language (103), Arabic language (160), raising a child (114).

\section{The study sample:}

The research sample consisted of (305) female students, from first-year students, admitted for the academic year (2019-2020).

\section{Sample selection method:}

The sample was chosen in an intentional way, whereby the standards were sent to the professors who study the first year subjects and the number of students from their people exceeded 50)) and cooperate with them to answer the scales to facilitate the application that took place during the quarantine period, specifically April 2020.

\section{Instruments of the study:}

After reviewing the theoretical literature and with the help of the Birx List of Behavior, the two tools of the study were developed, namely the Positive thinking scale, which reached the number of its statementsin the final image (27) statements, and the Behavioral disorders scale, and the number of its statements(50) statements.

Exploratory application: 
The scales were presented to a number of arbitrators and their opinions on modifying or canceling the text of the statement were taken into account by (3) of (10) arbitrators, and then the two scales were applied to a sample of (30) students from outside the sample to ensure the validity of the scale.

Variables of the study:

Positive thinking, Behavioral disorders, where the school year variable was set by choosing the first school year

\section{Study results and their interpretation}

The first question: What is the level of Positive thinking among the students of Princess High University College?

To answer this question, the arithmetic mean and standard deviation of Positive thinking among the female students of Princess High University College were extracted, and the table below shows that.

The arithmetic mean and standard deviations of the level of Positive thinking among female students of Princess High University College

\begin{tabular}{|r|c|c|c|}
\hline & Mean & S.D & level \\
\hline $\begin{array}{c}\text { Positive } \\
\text { thinking }\end{array}$ & 21.32 & 5.274 & high \\
\hline
\end{tabular}

The table shows that the arithmetic mean of the positive thinking level of the Princess High University College students reached (21.32), with a standard deviation of (5.274), and with a high level.

The second question: What is the level of Behavioral disorders among Princess High University College students?

To answer this question, the arithmetic mean and standard deviation of the level of Behavioral disorders of Princess High University College students were extracted, and the table below shows that.

The arithmetic mean and standard deviations of the level of Behavioral disorders among students of Princess High University College

\begin{tabular}{|r|c|c|c|}
\hline & Mean & S.D & level \\
\hline $\begin{array}{c}\text { Positive } \\
\text { thinking }\end{array}$ & 27.50 & 13.435 & low \\
\hline
\end{tabular}

The table shows that the arithmetic mean of the level of Behavioral disorders among Princess High University College students reached (27.5), with a standard deviation of (13.435), and with a low level.

The third question: Is there a statistically significant correlation between the level of Positive thinking and Behavioral disorders among students of Princess High University College?

To answer this question, the Pearson correlation coefficient between Positive thinking level and the level of Behavioral disorders of Princess High University College students has been extracted, and the table shows that.

Pearson correlation coefficient for the correlation between Positive thinking and Behavioral disorders among Princess High University College students

\begin{tabular}{|r|c|c|}
\hline & & Disorders \\
\hline & $\mathrm{R}$ & $-.346(* *)$ \\
\cline { 2 - 3 } $\begin{array}{r}\text { Positive } \\
\text { thinking }\end{array}$ & Sig & 0.000 \\
\cline { 2 - 3 } & Number & 305 \\
\hline
\end{tabular}

* Statistical significance at the significance level (0.05).

** Statistical significance at the level of significance (0.01).

Table (5) shows that there is a negative statistically significant correlation between the level of Positive thinking and Behavioral disorders among students of Princess High University College. 


\section{Discussion of the results:}

This chapter discusses the results of the research, in which it aims to reveal the level of Positive thinking and its correlation to the level of Behavioral disorders among the female students of Princess Aley University College, in light of the study questions.

\section{The results of the first question:}

The results of the first question showed that the arithmetic average of the positive thinking level of the students of Princess High University College reached (21.32), with a standard deviation of (5.274), and with a high degree of appreciation, indicating an increase in the level of Positive thinking among the research sample, which was about $(47 \%)$ From the study community, who are first-year students, who are students who have started a qualitatively different stage of their academic life in an educational institution that differs significantly from the school, and they have achieved success at the level of high school and every student of this stage and after its success is full of energy and enjoys the beginning of independence and greater self-reliance and the system Less burden education for students than high school.

Each one has reached a goal for which the school years have worked, and the subjects of the first year students are usually limited subjects, the academic burden is little, and the nature of the subjects is simple and basic content, which has the greatest impact on reducing the psychological burden on the students, and thus the student's status and her psychological and cognitive skills are not affected. I carried her to this period, which is a dream of escape, which increases positivity in his mental skills and behavior, and it is also the result of all studies that dealt with the level of positive thinking among university students, and also confirmed that increasing the level of Positive thinking increases motivation, mental health and positive habits, Including the study of Abdullah (2017), the study of Al-Sayed (2016), the study of Muttrash and Dredd (2013).

\section{The results of the second question:}

The results of the second question showed that the arithmetic mean of the level of Behavioral disorders among Princess Alia University College students reached (27.5), and a standard deviation reached (13.435), and with a low degree of appreciation, and this result may be attributed to the fact that the most common causes of Behavioral disorders are negative experiences experienced by the individual. It may also be pressures that diminish his ability to perform appropriately and adhere to accepted standards of behavior, which we can exclude from the behavior predictions of students who have succeeded in passing secondary school and joined the university and live a new positive experience in their scientific practical life and this enhances the positive environment that has a deeper role in shaping behavior The individual and their trends. Previous studies revealed the presence of varying rates of types of disorders among university students, including the study of Toth et al. (2018), the study of Diaspora and others (2014), the study of Lay and others (2014), the study of Axio (2003), and also the study of Ansari (1997).

\section{The results of the third question:}

The results indicate a statistically significant negative correlation between the level of Positive thinking and Behavioral disorders among students of Princess High University College, which enhances the results of the first and second questions and the logical correlation between the high level of mental skills and the positive performance of the individual and avoiding various negative behaviors. This is confirmed by the theoretical literature related to positive psychology, which indicates that the acquisition and development of cognitive mind skills and optimism guides the performance of the individual desired behavior and adherence to values and increases the level of adaptation and promotes mental health which would avoid the individual negative behaviors and various Behavioral disorders, namely It also agreed with the studies of Chenafeh (2017), Chechnya Wong study 
(2012), Seljman's study (2006), and thestudy ofGirk and Wow Palosimons (2000), all of which came to the same conclusion that Positive thinking increases mental health and adaptive capabilities, which enhances Positive behavior and reduces the incidence of behavioral disorders, and that all these studies were on the same age group of university students.

\section{Recommendations:}

1. The necessity of investing the students' open-minded skills in academic and non-academic activities, which increases learning opportunities and contributes to positive self-construction and creativity in the performance of students.

2. Development of positive thinking-based programs and their skills for treating Behavioral disorders among students who suffer from Behavioral disorders and the psychological pressures that cause various Behavioral disorders.

3. The result also indicates the importance of including positive cognitive skills in teaching, which provides ways of psychological support and avoids students developing behavioral disorders.

\section{References:}

1. Bono, Edward D. (2001): Positive thinking caps, translated by Khalil al-Jayyousi, Abu Dhabi, Al-Majmou al-Thaqafi.

2. W, Scott (2003), The Power of Positive Thinking in Businesstranslated by NowruzAsaad, Al-Obeikan, Saudi Arabia

3. Beaver Vera (2011): Positive thinking, 8th floor, Riyadh, Al-Jarir Library for Printing and Publishing.

4. Al-Sayed, Shaima, (2016) Positive thinking and its correlation to the achievement motivation of high school technical commercial students "A predictive correlational study" published master thesis, Journal of the Faculty of Education - Port Said University, Issue 20.

5. Abu Alya, Muhammad, and Melhem, Abdul Qadir (1998) as the effectiveness of the resource room program in reducing behavioral problems among a sample of those with academic educational difficulties from the third and fourth grades students in a school in Amman. Mu'ta for Research and Studies, Vol. 16, Vol. 13, pp. 11-39.

6. Al-Rimawi, Mohamed Odeh. (2004): General Psychology, Amman, Dar Al Masirah for publishing, distribution and printing.

7. Ibrahim, Abd Al-Sattar (2008) Eye of Mind, "A Psychotherapist's Guide to Positive Cognitive Therapy", Cairo Kadar Al-Kitab.

8. Mutrash, Muntaha and Dredd, Suzan (2014), Positive thinking and its correlation to some variables among students of the College of Education at the Universities of Baghdad and AlMustansiriya, Journal of Psychological Research (41).

9. Al-Ansari, Badr (1997) Psychological problems among young people of both sexes in Kuwait, research presented to the Eighth International Conference of the World Assembly of Muslim Youth entitled Muslim Youth and Contemporary Challenges,

Riyadhhttp://uqu.edu.sa/kahadri/ar/73128

10. Al-Ansari, Badr Al-Din (2000), Personality Scalement, Kuwait, The Modern Book House.

11. Beck, Aaron (2000), translated by: Dr. Adel Mustafa, Publisher: Dar Al-Nahda Al-Arabiya, Beirut.

12. Al-Sultani, Azimah (2010) The Impact of the Hajar Shady Approach for the Development of Positive Thinking on the Perception of Youth Players in Basketball, Journal of Science of Sports Education, University of Babylon.

13. Debono, Edward (2001) Teaching Thinking, translated by: Abd alKarimiyasin, and others. Dar Al-Redha, Damascus, i 1.

14. Mahbobeh Chinaveh1, Seyedeh Fatemeh Tabatabaee,(2017) Mental Health 
Rehabilitation Based on Positive Thinking Skills Training, Arsanjan Branch, Islamic Azad University, Iran

15. Grek, B， Obiala,R\& Simmons(2000); Effectiveness of the program for the development of positive thinking in students exbosed to psychological pressyre S.

16. E Kiss-Tóth, M Wasilewska, O Sopel, M Mandziuk, J Ladner, B Varga, P Sasvári, A Lukács,(2018) Eating disorder in university students: an international multiinstitutional study,European Journal of Public Health, Volume 28, Issue suppl_4, November 2018, cky214.010, https://doi.org/10.1093/eurpub/cky214.010

17. Sullivan, H. S. (1953). The interpersonal theory of psychiatry. New York:Norton

18. Quay, H. C., \& Werry, J. S. (1972). Psychopathological disorders of childhood. John Wiley \& Sons

19. Apter. M. J. (1989). Motivation; Emotion and Personality, London: Routledge.

20. Kauffman, J. M. Characteristics of children's behavior disorders. Columbus, Ohio: Charles E. Merrill, 1977.

21. Aldibat.Khaldoun,Matani, Nasir, Le Naenec,Carole-Lynne,(2014),Mental

Health Among Undergraduate UniversityStudents; A background paper for administrators, educators and healthcare providers, universal journal of public health 2(8);209-214.

22. Seligman, M.(1991)Learned optimism the skill to counter life obstacles, large and small, New York, Random House.

23. Seligman, $M$ et al.(2002), srenghs of character and wellbeing. Journal of social and clinical psychology, vol23,pp.603619.

24. Wong,Shyshin(2012), Negative thinking versus positive thinking in a Singaporean students sample. Relationships with psychological wellbeing and psychological maladjustment. Learning and individual differences,22(1),Feb2012,pp.76-82.
25. Laei,Soosan, Ali Abdi, karamaerouz,mohammad,shirkhani,nassim (2014),the impact of behavioral-social disorder on student's education dropoff,universal journal of educational research2(3):207-212,2014.

26. Seligman, M.(2003) Authentic happiness : using the new positive psychology to realise your potential for lasting fulfilment, amazon.co.uk

27. Xue,wang.,xu neng feng, qu shu-ming et al.(2007)female college students: the employed anxiety and its relationship with mental health, public health institute, Chinese journal of school doctor, Fujian, china. 